\title{
Endoscopic features of gastrointestinal tuberculosis and crohn's disease
}

\author{
Praneeth Moka, Vineet Ahuja, Govind K. Makharia
}

Department of Gastroenterology and Human Nutrition, All India Institute of Medical Sciences, New Delhi, India

\begin{abstract}
\end{abstract}
\section{Introduction}

Extrapulmonary tuberculosis (TB) accounts for approximately $20 \%$ of patients having TB and $7 \%-10 \%$ of them have abdominal TB. ${ }^{[1-3]}$ While abdominal TB continues to be a common problem in developing countries including India, increasing population migration and epidemic of acquired immunodeficiency syndrome have led to resurgence of this disease in regions where TB had previously been largely controlled. ${ }^{[1-3]}$ Abdominal TB remains an important disease in

Address for correspondence:

Dr. Govind K. Makharia, Department of Gastroenterology and Human

Nutrition, All India Institute of Medical Sciences, Ansari Nagar,

New Delhi - 110 029, India.

E-mail: govindmakharia@gmail.com

\begin{tabular}{|l|c|}
\hline \multicolumn{2}{|c|}{ Access this article online } \\
Website: & Quick Response Code \\
www.jdeonline.in & \\
DOI: & 10.4103/jde.JDE_48_16
\end{tabular}

countries where TB is still endemic. ${ }^{[1-7]}$ While TB is endemic in India, there has been a rise in number of patients with Crohn's disease (CD) from every part of India. ${ }^{\left[{ }^{8,9]}\right.}$ In a study by the Indian Society of Gastroenterology Task Force on inflammatory bowel disease (IBD) including 1159 patients with IBD from secondary and tertiary care centers in India, $35.3 \%$ of them had CD. ${ }^{[10]}$

The clinical, morphological, and histological features of gastrointestinal (GI) TB and CD are so similar that it becomes difficult to differentiate between these two entities. ${ }^{[1-14]}$ In geographical regions such as India where both GI TB and $\mathrm{CD}$ are prevalent, differential diagnosis between the two is challenging. ${ }^{[11-14]}$ The natural history of $\mathrm{CD}$ is quite different from that of GI TB. While GI TB gets cured with appropriate

This is an open access article distributed under the terms of the Creative Commons Attribution-NonCommercial-ShareAlike 3.0 License, which allows others to remix, tweak, and build upon the work non-commercially, as long as the author is credited and the new creations are licensed under the identical terms.

For reprints contact: reprints@medknow.com

How to cite this article: Moka P, Ahuja V, Makharia GK. Endoscopic features of gastrointestinal tuberculosis and crohn's disease. J Dig Endosc 2017;8:1-11. 
anti-TB treatment, CD has a remitting/relapsing or persistent course and stays life-long usually. Although treatment with an immunosuppressant with a mistaken diagnosis of $\mathrm{CD}$ may worsen TB, an empiric treatment with anti-TB therapy on the other hand may delay the diagnosis of $\mathrm{CD}$ in such patients. Furthermore, use of biologics, which have become one of the important treatment modalities for $\mathrm{CD}$, can lead to flare of $\mathrm{TB}$ if the mistaken diagnosis of $\mathrm{CD}$ is made in a patient having GI TB. ${ }^{[15-17]}$ Because of similarity in the clinical presentation, endoscopic appearance, and histological characteristics between these two diseases, many of them are treated empirically with anti-TB drugs at times. ${ }^{[9,18]}$

\section{Diagnostic Criteria}

\section{Diagnostic criteria for gastrointestinal tuberculosis}

A definitive diagnosis of GI TB can be made based on the presence of any of the following three criteria:

- Culture of tissue (colonic biopsy, lymph nodes) resulting in growth of Mycobacterium tuberculosis

- Histological demonstration of typical acid-fast bacilli (AFB)

- Histological evidence of necrotizing granuloma.

While a positive culture, demonstration of $\mathrm{AFB}$ on smear, and histological evidence of a caseating granuloma are gold standard tests for the definitive diagnosis of $\mathrm{TB}$, the sensitivity of the combination of the three or any one test is approximately $30 \%-50 \% \cdot{ }^{[19]}$ In rest of the patients, the diagnosis is considered presumptive based on clinical, endoscopic, radiological, and histological evidence. The unequivocal response to anti-TB therapy for 6 months confirms the diagnosis of TB in these patients. It should be emphasized that adherence to treatment is extremely important in those with presumptive diagnosis of TB who are receiving anti-TB therapy empirically.

\section{Diagnostic criteria for Crohn's disease}

There is no single gold standard test, and the diagnosis of CD is based on a combination of clinical features, endoscopic characteristics, and histological characteristics. Both the
Asian Pacific Associations of Gastroenterology and the Indian Society of Gastroenterology guidelines on CD suggest exclusion of infective causes, especially TB before making a diagnosis of CD. ${ }^{[20,21]}$

\section{Sites of Involvement in Gastrointestinal Tuberculosis and Crohn's Disease}

TB may involve any part of GI tract (GIT), from the esophagus to the anal canal. There is a striking tendency for intestinal TB to affect the ileum and ileocecal (IC) area preferentially. ${ }^{[22]}$ Other common sites of involvement in TB are colon, appendix, and jejunum [Table 1]. In the colon, the frequency of involvement decreases segmentally from the ascending colon to the rectum. The involvement of rectum and anal canal is uncommon in patients with GI TB. Patients with TB may have involvement of lymph nodes, peritoneum, and solid viscera either alone or in combination with GIT.

\section{Types of Morphological Lesions}

The changes caused by acute inflammation of the colonic mucosa, namely, edematous mucosal folds, mucosal ulcerations and nodularity, luminal narrowing, strictures, and pseudopolyps, can occur in both intestinal TB and CD. The morphological features of intestinal TB (ITB) and CD depend on the stage of the disease. The lesions may vary from mild lesions such as loss of vascular pattern, erythema, and superficial ulcerations to more advanced lesions including deep ulcerations, nodularity, and strictures. One should realize that the evolution of disease takes from months to years both for GI $\mathrm{TB}$ and $\mathrm{CD}$. The classical morphological features, as described in most textbooks, are seen in advanced stages of the disease. Some of the patients may present in early stages of evolution of the disease, thereby one may not find classical lesions and instead finds minute lesions. The wisdom lies in identifying these minute lesions so that the progression of the disease can be prevented with timely institution of appropriate treatment. Table 2 shows the types of lesions and their characteristics for universal reporting.

\begin{tabular}{|c|c|c|c|c|c|c|}
\hline \multirow[t]{2}{*}{ Site } & \multicolumn{2}{|c|}{ Amarapurkar et al..$^{[8]}$} & \multicolumn{2}{|c|}{ Makharia et al. ${ }^{[23]}$} & \multicolumn{2}{|c|}{ Li et al. ${ }^{[24]}$} \\
\hline & $\operatorname{CD}(n=26)(\%)$ & ITB $(n=26)(\%)$ & $\operatorname{CD}(n=53)(\%)$ & ITB $(n=53)(\%)$ & $\operatorname{CD}(n=130)(\%)$ & ITB $(n=122)(\%)$ \\
\hline Stomach & 0 & $2(7.7)$ & $3(5.6)$ & $1(1.8)$ & & \\
\hline Duodenum & $1(3.8)$ & $2(7.7)$ & $3(5.6)$ & $2(3.7)$ & & \\
\hline Jejunum & $2(7.7)$ & $1(3.8)$ & $9(16.9)$ & 0 & & \\
\hline lleum & $16(61.5)$ & $20(76.9)$ & $13(24.5)$ & $8(15)$ & $86(66.2)$ & $73(59.8)$ \\
\hline Ileocecal region & $20(76.9)$ & $21(80.7)$ & $47(88.6)$ & $49(92.4)$ & $72(55.4)$ & $92(75.4)$ \\
\hline Ascending colon & $18(69.2)$ & $21(80.7)$ & $34(64.1)$ & $23(43.4)$ & $60(46.2)$ & $76(62.3)$ \\
\hline Descending colon & $10(38.4)$ & $5(19.2)$ & $32(60.3)$ & $7(13.2)$ & $44(33.8)$ & $30(24.6)$ \\
\hline Sigmoid colon & & & $35(66.3)$ & $6(11.3)$ & $58(44.6)$ & $28(23)$ \\
\hline Rectum & $8(30.7)$ & $5(19.2)$ & $33(62.2)$ & $10(18.8)$ & $50(38.5)$ & $20(16.4)$ \\
\hline Anal canal & $2(7.7)$ & $1(3.8)$ & $8(15)$ & $2(3.7)$ & & \\
\hline
\end{tabular}

$\mathrm{CD}=$ Crohn's disease, ITB=Intestinal tuberculosis 


\begin{tabular}{|c|c|c|}
\hline Mucosal damage & Description & Grading \\
\hline $\begin{array}{l}\text { Loss of vascular } \\
\text { pattern }\end{array}$ & $\begin{array}{l}\text { Loss of normal mucosal appearance without } \\
\text { well-demarcated, arborizing capillaries }\end{array}$ & From patchy or blurred to complete loss \\
\hline Erythema & Unnaturally reddened mucosa & From discrete or punctiform to diffuse erythema \\
\hline Granularity & $\begin{array}{l}\text { Mucosal pattern produced by a reticular network of } \\
\text { radiolucent foci of } 0.5-1 \mathrm{~mm} \text { of diameter with a sharp light } \\
\text { reflex }\end{array}$ & $\begin{array}{l}\text { From fine to coarse or nodular due to abnormal light } \\
\text { reflection }\end{array}$ \\
\hline Friability/bleeding & $\begin{array}{l}\text { Bleeding or intramucosal hemorrhage before or after the } \\
\text { passage of the endoscope }\end{array}$ & $\begin{array}{l}\text { From contact bleeding (bleeding with light touch) to } \\
\text { spontaneous bleeding }\end{array}$ \\
\hline Erosion & $\begin{array}{l}\text { A definite discontinuation of mucosa }<3 \mathrm{~mm} \text { in size. Also } \\
\text { described as pinpoint ulceration }\end{array}$ & Isolated, diffuse \\
\hline Aphthous ulcer & White depressed center surrounded by a halo of erythema & Isolated, multiple \\
\hline Ulcer & $\begin{array}{l}\text { Any lesion of the mucosa of unequivocal depth with or } \\
\text { without reddish halo }\end{array}$ & $\begin{array}{l}\text { Isolated or multiple based on morphology: Circular, linear, } \\
\text { stellar, serpiginous, irregular shape, superficial or deep }\end{array}$ \\
\hline Ulcer size & $\begin{array}{l}\text { Defined in } \mathrm{mm} \text { or classified as: } \leq 5 \mathrm{~mm} ; 5-20 \mathrm{~mm} ;>20 \\
\mathrm{~mm}\end{array}$ & \\
\hline Stenosis & Narrowing of the lumen & $\begin{array}{l}\text { Single, multiple, passable (by standard adult endoscope), } \\
\text { un-passable, passable after dilation, ulcerated, nonulcerated }\end{array}$ \\
\hline $\begin{array}{l}\text { Postinflammatory } \\
\text { polyps }\end{array}$ & $\begin{array}{l}\text { Polypoid lesion, usually small, glistering, isolated or } \\
\text { multiple, scattered throughout the colon }\end{array}$ & Isolated, diffuse, occluding (“giant”) \\
\hline & Sometimes cylindrical or giant $(>2 \mathrm{~cm})$ in size & \\
\hline Cobblestone & $\begin{array}{l}\text { Mucosal pattern with raised nodules, resembling the } \\
\text { paving of a "roman" road }\end{array}$ & With or without ulceration \\
\hline
\end{tabular}

\section{Pathological and Clinical Correlation}

The diameter of a normal intestine decreases from the duodenum to jejunum and then to the ileum. The diameter of the jejunum is $3 \mathrm{~cm}$ and that of the ileum is $2.5 \mathrm{~cm} \cdot{ }^{[25,26]}$ The content, which flows through the intestine, is mostly chyme (liquid). The diameter of the intestinal lumen, at which the obstruction to the flow of chyme occurs, is not well established. In a rat model, it was observed that the pressure in the intestine started rising and the flow of the contents started decreasing when the luminal diameter decreased to $60 \%$ of the original diameter. ${ }^{[2]}$ Therefore, in the early stage of diseases, when there is no cicatrization of the lumen, the flow of chyme is not affected and thus patients may not have any intestinal symptoms. With progression of the disease, the effective diameter of the intestinal lumen decreases, resulting in obstruction to the flow of the intestinal contents. Therefore, the severity of symptoms increases progressively as the intestinal luminal diameter decreases. The initial symptoms of intestinal colic are usually episodic and are precipitated by the episodes of GI infection resulting in transient mild intestinal wall edema which further compromise the diameter of the already compromised intestinal lumen because of the disease process. While inflammation caused by acute GI infection in the normal intestine is not critical and does not lead to critical decrease in the effective diameter of the intestine, even a mild decrease in the diameter of the intestine can lead to a critically low diameter in already compromised lumen due to the primary disease process. Such episodic symptoms may also be precipitated by a high fiber diet or the ingestion of seeds. As disease progresses, the interval between the episodes of symptoms also decreases. Ultimately, the symptoms of intestinal colic become more frequent and patients develop partial intestinal obstruction. The ulcerations and nodularity caused by the tissue destruction can lead to oozing of blood from the ulcers, resulting in anemia.

After effective treatment of the disease, there is resolution of active inflammation and healing of ulcers, which results in the improvement in symptoms. As it is well known that chronic inflammatory process heals with fibrosis, the healing of ulcers and inflammation of the intestine leads to scarring of the intestinal lumen and thus compromise the normal intestinal diameter. ${ }^{[28]}$ There is a fundamental difference in the diseases affecting solid/spongy organs and luminal organs. In spite of residual changes in a part of the solid/spongy organ, there still may be sufficient organ volume to maintain the functions of the organ. On the contrary, healing of the intestinal lesions may result in the fibrotic stricture and patients may continue to be symptomatic. Most of the times, however, despite the residual intestinal stricture/narrowing, the luminal diameter may remain sufficient to allow uninterrupted the passage of intestinal contents. On occasions, healing of lesions can result in a critical stricture resulting in frequent symptoms and such strictures may require resection or stricturoplasty.

\section{Endoscopy in Intestinal Tuberculosis and Crohn's Disease}

Endoscopic examination of the GIT is essential not only for the diagnosis but also for evaluation the extent of the disease, assessment of the activity of the disease, and monitoring the response of the therapy in most patients with GI TB and CD.

Ileocolonoscopy is the first recommended test for the diagnosis of both ITB and CD. ${ }^{[20,21,29]}$ 


\section{Endoscopic features in patients with} gastrointestinal tuberculosis

IC region is most often involved area in patients having GI $\mathrm{TB}$, possibly because of the increased physiological stasis, increased rate of fluid and electrolyte absorption, minimal digestive activity, and an abundance of lymphoid tissue at this site. ${ }^{[30-32]}$ Retrograde ileoscopy should be done in all patients suspected to have ITB and biopsies should be obtained even if the mucosa in the terminal ileum appears normal. The biopsies of normal appearing terminal ileum may reveal granulomas in additional $4 \%$ of patients with clinical suspicion of ITB. ${ }^{[33,34]}$ Terminal ileal involvement alone with relative cecal sparing is uncommon in ITB. ${ }^{[35]}$ In $10 \%-20 \%$ of patients, segmental colonic involvement may occur in the absence of IC involvement. ${ }^{[36,37]}$ Approximately 5\% of patients may present with pancolitis, which may mimic ulcerative colitis. ${ }^{[38]}$

The endoscopic findings in ITB may vary from mild lesion(s), such as loss of vascular pattern, erythema, small ulcerations, and superficial ulcerations, to more advanced lesions including deep ulcerations, nodularity, and strictures [Figure 1]. The endoscopic lesions in ITB are classified as ulcerative $(60 \%)$, ulcerohypertrophic (30\%) characterized by inflammatory mass around IC valve with ulcerated thick wall, and hypertrophic $(10 \%)$ characterized by fibrosis and pseudotumor lesions. ${ }^{[39]}$ The ulcers in ITB are typically transverse, often circumferential with ill-defined, sloping or overhanging edges, and are usually surrounded by inflamed mucosa. ${ }^{[19,40-42]}$ The strictures in patients with TB are generally shorter in length. IC valve is often patulous in them [Figure 1]. A stricture in the intestine has also been described due to extraluminal cause such as lymph nodes causing compression even without apparent mucosal lesion. ${ }^{[6]}$

In tuberculous colitis, the colonic mucosa surrounding an ulcer exhibits features of inflammation, such as erythema, nodularity, or edema. The rectum is rarely involved. ${ }^{[43]}$ Traction diverticula and sinus tracts due to adjacent lymphadenitis may be seen in tubercular colitis. ${ }^{[39]}$

In gastroduodenal $\mathrm{TB}$, comprising $1 \%$ of abdominal $\mathrm{TB}$, the most common endoscopic findings observed are ulceration and nodularity in the pyloroduodenal area along with strictures, and the disease could be multifocal, involving pyloroduodenal area and the second part of the duodenum (15\%) or even present as antral hypertrophic nodular mass. ${ }^{[40]}$

\section{Endoscopic features in Crohn's disease}

CD can affect any part of the GIT, from the oropharynx to the anorectum. Once CD has settled in, the location of the disease remains stable generally, although exceptions do occur, especially following surgical resections ${ }^{[41]}$ [Table 1]. Similar to $\mathrm{TB}, \mathrm{CD}$ also affects IC area commonly. ${ }^{[42]}$ In a multicenter study conducted by the Indian Society of Gastroenterology, of 397 patients with CD, 39.2\% had involvement of both small and large intestine (ileocolonic), 31.2\% had isolated colonic, and $22.9 \%$ had involvement of only small intestine. The involvement of upper GI (UGI) was reported in $5.8 \%$ of patients. While $18.8 \%$ had stricturing disease, $4.4 \%$ had fistulizing disease. Nearly $6.9 \%$ patients had perianal disease as a disease modifier. ${ }^{[10]}$

Isolated perianal disease is rare $(2 \%-3 \%)$ although perianal abnormalities, in conjunction with other sites of intestinal involvement, are common. ${ }^{[43-45]} \mathrm{UGI}$ involvement, when occurs in patients with $\mathrm{CD}$, it almost always occurs in association with small intestinal and/or colonic involvement.

The earliest and most characteristic endoscopic finding in $\mathrm{CD}$ is the aphthous ulcer. ${ }^{[46,47]}$ It can be found throughout the GIT. An aphthous ulcer represents a small ( $\leq 5 \mathrm{~mm})$ superficial ulcer surrounded by a characteristic tiny rim of erythema [Figure 2]. They have clear margins and are often surrounded by normal colonic mucosa with very little reactive change. Aphthous ulcers can be localized or multifocal. ${ }^{[48]}$ They are often seen in groups and lie in longitudinal fashion in the GIT, tend to enlarge concentrically, become nodular, and give rise to larger and deeper ulcerations. ${ }^{[46]}$ The best model to study the earliest lesions in $\mathrm{CD}$ is the postoperative recurrence condition, where these early lesions recur within weeks to months after surgery. ${ }^{[46]}$

The ulcers in CD can be of various sizes and shapes. The mucosa lying between long linear ulcerations can be normal or very edematous, reddish, and hyperplastic, giving an appearance of cobblestone [Figure 2]. ${ }^{[49]}$ The involvement of the colon and small intestine in patients with $C D$ is characteristically patchy. The lesions may involve only one side of the colonic mucosa in the same segment [Figure 3]. Rectum is involved in approximately 50\% [Figure 2].

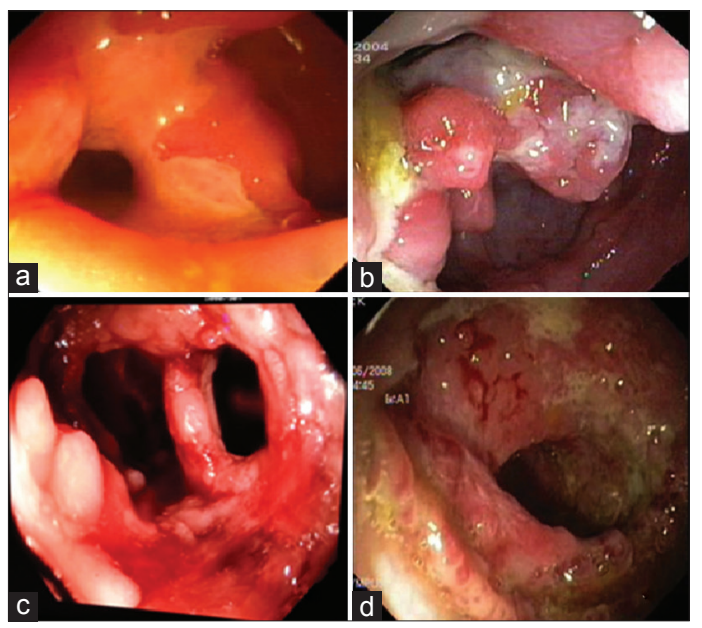

Figure 1: Endoscopic lesions in a patient with intestinal tuberculosis. (a) Ulcers over the ileocecal valve in a patient with intestinal tuberculosis. (b) Multiple nodules and deep ulcers (with neoplasm-like appearance) in cecum with patulous ileocecal valve. (c) Fixed patulous ileocecal valve with nodules in cecum and ascending colon in a patient with intestinal tuberculosis. (d) Circumferential ulcerative lesion in a patient with tuberculosis 


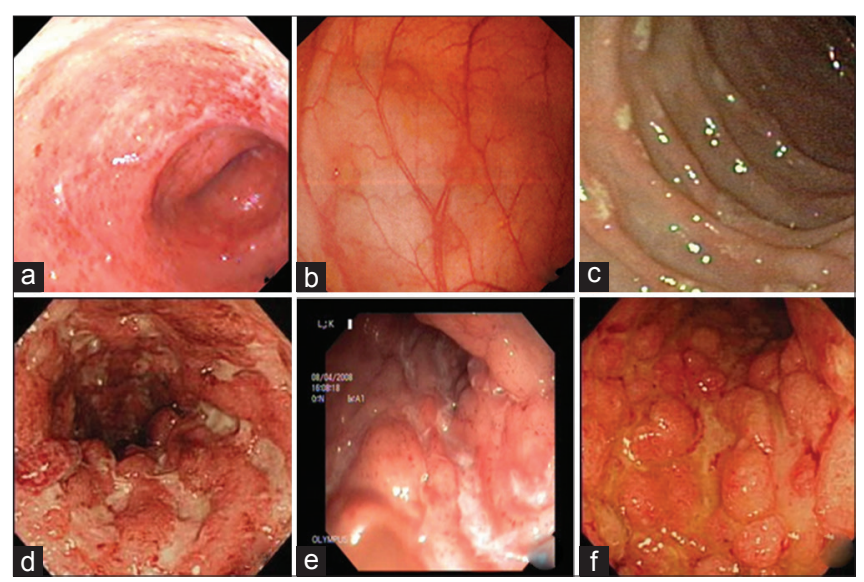

Figure 2: Endoscopic features in a patient with Crohn's disease. (a) Erythema and loss of vascular pattern in a patient with Crohn's disease. (b) A few aphthous ulcers in the colon in a patient with Crohn's disease. (c) Discrete ulcers in the colon in a patient with Crohn's disease. (d) Multiple deep longitudinal ulcers in colon in a patient with Crohn's disease. (e) Longitudinal ulcers with cobblestone appearance in the colon. (f) Cobblestone appearance in a patient with Crohn's disease

Where the inflammation is deep and extensive, luminal narrowing or strictures can occur. ${ }^{[48,49]}$ Strictures virtually always arise in areas having severe ulceration. Both length and width of the strictures can vary considerably, $3-10 \mathrm{~cm}$ in length. ${ }^{[42]}$ The strictures in patients with $\mathrm{CD}$ may be longer than that seen in patients with TB. Strictures with surrounding nodularity and eccentric lumen may also be due to malignant transformation. ${ }^{[50]}$ The inflammation and ulcerations in $\mathrm{CD}$ are often deep, transmural, and can lead to perforation, inflammatory mass, and/or fistula formation. Fistulas are most often seen proximal to strictures or within the strictures and are frequently surrounded by extensive inflammatory changes. ${ }^{[51]}$

When $\mathrm{CD}$ becomes quiescent, vascular pattern may remain diminished. In patients with more extensive $C D$, irregular healing may lead to hypertrophic zones alternating with areas of atrophy (pseudopolyps) and mucosal bridging.

\section{Upper gastrointestinal involvement in Crohn's disease}

UGI endoscopy is routinely performed in the assessment of children with suspected IBD to accurately classify IBD ${ }^{[52]}$ While UGI endoscopy and biopsies may be useful in all patients for evaluation of the extent/location of the disease at the time of diagnosis, whether it should be performed routinely in all adult patients remains unclear. ${ }^{[52]}$ The UGI endoscopy, however, should be done in at least in those who have UGI symptoms.

Isolated involvement of UGI tract is rare in patients with $\mathrm{CD}$, and whenever there is an involvement of UGI tract, it occurs concomitantly with the involvement of either small intestine or the colon or both. ${ }^{[53]}$ Gastroduodenal involvement often presents with additional symptoms such as epigastric pain and features of high-gut obstruction. The ulcers in the gastroduodenal CD may be linear or serpiginous, unlike

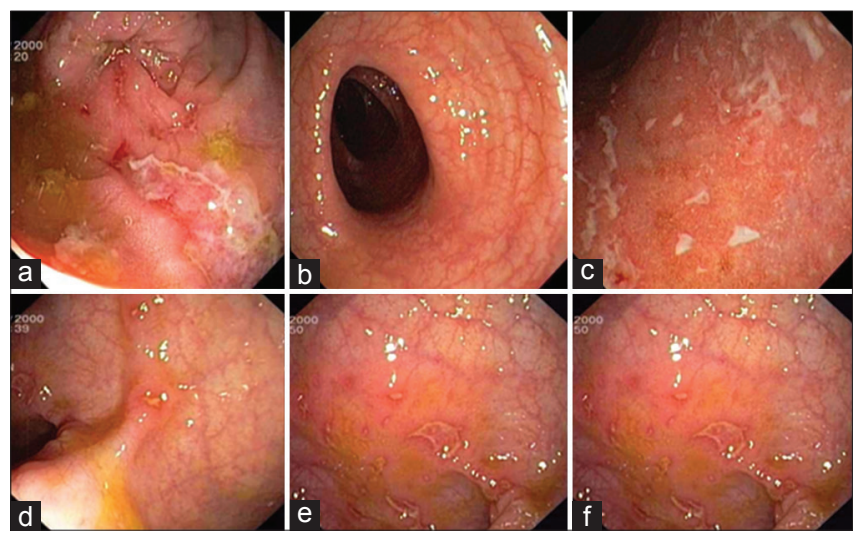

Figure 3: Skip lesions in a patient with Crohn's disease. (a) Discrete ulcerated lesion in the rectosigmoid region. (b) Normal looking mucosa in the descending colon. (c) Multiple ulcers with loss of vascular pattern in transverse colon. (d) Discrete ulcers in the ascending colon. (e and f) Discrete ulcers in the cecum

circular or transverse ulcers seen in peptic ulcer disease, which involves gastroduodenal area far more often than $\mathrm{CD} \cdot{ }^{[54]} \mathrm{In}$ isolated duodenal disease, any part of the duodenum can be involved, but the second part is most frequently affected. Deep ulceration and inflammation can lead to stricture in gastroduodenal area and high-gut obstruction.

Diaz et al. in a review of 20 articles reporting 2511 patients with $\mathrm{CD}$ (CD group) reported involvement of UGI tract in $815(34 \%)$ patients (UGI group). ${ }^{[5]]}$ The endoscopic features in the $\mathrm{CD}$ group were gastric erythema in $5.9 \%$, gastric erosions in $3.7 \%$, duodenal ulcers in $5.3 \%$, and erythema in the duodenum in $3 \%$ of patients. ${ }^{[55]}$ The most common histopathological features in the $\mathrm{CD}$ group was nonspecific gastric inflammation in $32 \%$, gastric granuloma in $7.9 \%$, and focal gastritis in $30.9 \%$ of patients. ${ }^{[5]}$ In the UGI CD group, gastric inflammation was present in $84 \%$ of patients, followed by duodenal inflammation in $28.2 \%$ and gastric granuloma in $23.2 \%$. The detection of UGI tract involvement is higher ( $17 \%-75 \%$ for upper endoscopy) when biopsies of gastric mucosa are done routinely in patients with CD compared to the practice when UGI endoscopy and biopsies are done only if one observes any abnormality in symptomatic patients $(0.5 \%-13 \%))^{[53,55]}$

\section{Endoscopy during Follow-up of Patients}

In patients treated for intestinal $\mathrm{TB}$, it is expected that there will be complete resolution of the lesions, detectable by endoscopy or by imaging, following completion of therapy. In a study of 49 patients with IC or colonic TB treated with anti-TB treatment, complete healing of mucosal lesions was observed in $73.5 \%$ of the participants at the end of 2 months and in $100 \%$ of participants at the end of 6 months. ${ }^{[56,57]}$ It is therefore appropriate to re-endoscope patients who were treated empirically for ITB and to establish complete mucosal healing at the end of 6 months. The Indian Society of Gastroenterology Task Force on IBD was in agreement that 
this should be done, in view of the possibility that recurrent symptoms would make it difficult to judge whether the patient was in fact having ITB or CD during the first episode.

There is now emerging evidence that mucosal healing should be one of the goals of the treatment of CD. Therefore, it appears appropriate that the status of healing process is assessed during the treatment period. While many agree to do that, the protocol and timing of assessment is yet to be defined.

When diagnosis remains in doubt, both endoscopic and histologic assessments are appropriate as demonstrated by a large proportion of patients initially classified as indeterminate colitis or possible IBD were diagnosed as non-IBD after 5 years $(22.5 \%$ vs. $50 \%)$ in the IBSEN study. ${ }^{[58]}$ In patients of definite ileocolonic $\mathrm{CD}$, routine endoscopic evaluation for patients in clinical remission may not always be necessary, unless clinicians suspect that re-evaluation may have influence on the optimization of the management strategy. Fecal calprotectin or lactoferrin may be used as surrogate markers of mucosal healing and may reduce the need of repeated endoscopies. ${ }^{[59]}$

Ileocolonoscopy is the gold standard in the diagnosis of postoperative recurrence. It is recommended to be done at 6-12 months after surgery. After resection of the IC region in patients with $\mathrm{CD}$, the postoperative recurrence rate is around $65 \%-90 \%$ within 12 months and $80 \%-100 \%$ within 3 years of surgery in the absence of postoperative prophylaxis. ${ }^{[60,61]}$

\section{Mucosal biopsies}

With increasing use of endoscopic procedures to visualize the intestinal lumen and obtaining targeted biopsies from the diseased segments of the intestine, endoscopic mucosal biopsies have mostly replaced the surgical biopsies for microscopic examination. For a reliable diagnosis of CD, multiple biopsies from different segments of the colon (including the rectum) and the ileum should be obtained. ${ }^{[62]}$ Multiple biopsies imply a minimum of two samples from each site. ${ }^{[62]}$ Biopsies should be representative from areas of minor and major inflammation to mirror correctly the intensity and spectrum of inflammation. In addition, biopsies must also be taken from "normal appearing" mucosa. ${ }^{[62]}$ Targeted biopsies from areas of stenosis, any unusual polypoid lesions, or any other lesion that may attract endoscopists attention should be obtained in separate bottles. Biopsies should also be obtained for microbiological tests including molecular diagnosis of TB (polymerase chain reaction [PCR], GenExpert), acid-fast stain, and culture.

Isolation of $M$. tuberculosis, using culture or by staining of the smear, is the most specific method for the diagnosis of active TB. The sensitivity of both these techniques, however, remains low. ${ }^{[63-66]}$ While culture can detect $10-100$ bacilli/mL of the sample, $M$. tuberculosis bacilli can be cultured from $10 \%$ to $30 \%$ of mucosal biopsies in patients with colonic TB. ${ }^{[63-66]} \mathrm{A}$ presumptive diagnosis of TB may be considered by detection of AFB on intestinal biopsies which have been reported with a variable frequency $(25 \%-36 \%)$ in patients with intestinal TB. ${ }^{[19,67]}$

PCR using $M$. tuberculosis-specific primer shows a positivity varying from $20 \%$ to $64 \%$. Detection of $M$. tuberculosis by PCR has a fair sensitivity, but the results of a positive PCR should be interpreted cautiously. ${ }^{[19,68-70]}$ PCR may be reported positive because of contamination in the laboratories. Passage of saprophytic mycobacteria may also test positive in colonic biopsies. In one study, in situ PCR for TB in mucosal biopsies was positive in 6 of 20 intestinal TB patients. ${ }^{[63]}$

\section{Small Bowel Endoscopy}

In patients suspected of having intestinal $\mathrm{TB}$ or $\mathrm{CD}$, especially when ileocolonoscopy does not show definite evidence of the disease and contrast-enhanced computed tomography (CT) or CT-enterography (CTE) or magnetic resonance-enterography (MRE) shows small bowel wall thickening or stricture (with or without proximal bowel dilation), small bowel endoscopy may be needed to look for mucosal abnormalities suggestive of the disease and to obtain biopsies for histological assessment. Balloon-assisted and spiral enteroscopy are preferred modalities for evaluating the small bowel today because of biopsy and therapeutic capabilities. Histological assessment of the small intestinal lesion(s) is essential as the etiological diagnosis of the ulcerating lesions cannot be made based on endoscopic appearances alone. ${ }^{[71]}$ In patients with suspected $\mathrm{CD}$ and negative ileocolonoscopy, small bowel capsule endoscopy (SBCE) may be the diagnostic modality for the evaluation of the small bowel, in the absence of obstructive symptoms or known stenosis. The sensitivity and specificity for the diagnosis of CD have been reported to be $100 \%$ and $91 \%$ by SBCE, $81 \%$ and $86 \%$ by MRE, and $76 \%$ and $85 \%$ by CTE, respectively. ${ }^{[72]}$

In patients having intestinal obstructive features or known to have small intestinal stricture, a cross-sectional imaging modality such as MR-enterography or CTE is a preferable initial investigation. ${ }^{[52]}$

The data regarding capsule endoscopy in ITB are limited. Reddy et al. have described multiple scattered short, oblique, or transverse mucosal ulcers with a necrotic base in the jejunum and ileum in patients with ITB. ${ }^{[73]}$ Cello described the characteristics of small intestinal tubercular ulcers to be shallow with irregular geographic borders, and transverse in their lie, rather than longitudinal. ${ }^{74]}$

SBCE is a safe noninvasive modality for the diagnosis of CD. As per the results of a meta-analysis, SBCE is superior to all other modalities for diagnosing nonstricturing small bowel CD, with a number needed to test (NNT) of 3 to yield one additional diagnosis of $\mathrm{CD}$ over small bowel barium radiography and NNT of 7 over colonoscopy with ileoscopy. ${ }^{[75]}$ 
Fidder et al. defined a positive SBCE result for CD as the presence of four or more ulcers, erosions, or a region with clear exudate and mucosal hyperemia and edema. ${ }^{[76]}$ They reported that the greatest yield of SBCE in diagnosing CD is achieved in young patients who present with symptoms of abdominal pain plus diarrhea. ${ }^{[76]} \mathrm{SBCE}$ has a high negative predictive value for small bowel CD. ${ }^{[52]}$

Endoscopic differentiation of small bowel CD from druginduced lesions or other diseases is unreliable. Nonsteroidal anti-inflammatory drugs should be withdrawn at least 4 weeks before SBCE if there is a diagnostic possibility of $\mathrm{CD}^{\left[{ }^{[52]}\right.}$ The small lesions detected by SBCE may not be specific for CD and may be found in healthy people and patients with drug-induced enteropathy and vasculitis. In a study, among 102 patients with suspected $C D, 37 \%$ were initially found to have small bowel ulcerations on SBCE, but CD was diagnosed definitively in $13 \%$ only at 1 -year follow-up. ${ }^{[77]}$

The Capsule Endoscopy Crohn's Disease Activity Index (CECDAI) or Niv score has been recently validated in a multicenter prospective trial. ${ }^{[78,79]}$ This scoring index evaluates three parameters: inflammation (A), extent of disease (B), and presence of strictures $(C)$, both for the proximal and distal segments of the small bowel [Table 3]. The final score is calculated by adding the two segmental scores: CECDAI = proximal $([\mathrm{A} 1 \times \mathrm{B} 1]+\mathrm{C} 1)+\operatorname{distal}([\mathrm{A} 2 \times \mathrm{B} 2]+\mathrm{C} 2$.

CE may play an important role in the monitoring of patients with $\mathrm{CD}$ and may have a unique role in assessing mucosal healing after medical therapy, for assessing early postoperative recurrence. The role of SBCE in patients with established CD should focus on patients with unexplained iron deficiency or obscure GI bleeding or in those with unexplained symptoms, when other investigations are inconclusive. ${ }^{[52,80]}$

After a negative ileocolonoscopy and negative CTE or small bowel follow through, SBCE has not been found to be a

\begin{tabular}{lcl}
\hline $\begin{array}{l}\text { Table 3: Capsule endoscopy Crohn's disease activity } \\
\text { index }{ }^{[78]}\end{array}$ & Point & Features \\
\hline Score & 0 & None \\
\hline Inflammation & 1 & $\begin{array}{l}\text { Mild to moderate edema/hyperemia/ } \\
\text { denudation }\end{array}$ \\
score & 2 & Severe edema/hyperemia/denudation \\
& 3 & Bleeding, exudate, aphthae, erosion, \\
& & small ulcer $(<0.5 \mathrm{~cm})$ \\
& 4 & Moderate ulcer $(0.5-2 \mathrm{~cm})$, pseudopolyps \\
& 5 & Large ulcer $(>2 \mathrm{~cm})$ \\
Extent of & 0 & No disease \\
disease & 1 & Focal disease (single segment) \\
score & 2 & Patchy disease (2-3 segments) \\
& 3 & Diffuse disease (>3 segments) \\
Stricture & 0 & None \\
score & 1 & Single-passed \\
& 2 & Multiple-passed \\
& 3 & Obstruction (nonpassage) \\
\hline
\end{tabular}

cost-effective third test, even in patients with high pretest probability of CD. ${ }^{[81]}$ The International Conference on Capsule Endoscopy recommended that patients with suspected CD should be selected to undergo SBCE if they present with typical symptoms (chronic abdominal pain, chronic diarrhea, weight loss, or growth failure) plus either extraintestinal manifestations (fever, arthritis or arthralgia, pyoderma gangrenosum, perianal disease, or primary sclerosing cholangitis), inflammatory markers (iron deficiency, erythrocyte sedimentation rate, C-reactive protein, leukocytosis, or serology), or abnormal small bowel imaging (small bowel series or CT scan). ${ }^{[82]}$

The ability of CE in distinguishing between ITB and CD is not clearly established.

\section{Endoscopic Dilatation of the Strictures}

Endoscopic dilatation of strictures in CD is a safe and effective alternative to surgery in experienced hands and should be considered before surgery in selected patients. ${ }^{[52]}$ Endoscopic balloon dilatation has been used to treat uncomplicated strictures, with a maximal length of $4 \mathrm{~cm}$, in patients with CD. ${ }^{[83]}$ It has often been combined with local injection of steroids at the site of the stricture. Endoscopic dilatation should be done only after control of the disease activity. A systematic review of 13 studies including 347 patients with $C D$ showed that endoscopic dilatation was mainly used in postsurgical strictures, with $86 \%$ technical success, $2 \%$ complication rate, and $58 \%$ long-term efficacy. ${ }^{[84]}$ A stricture length equal to or less than $4 \mathrm{~cm}$ was associated with a surgery-free outcome. Another study including 776 dilatations in 178 patients with $C D$ further confirmed that the endoscopic dilatations had been done mostly for anastomotic strictures (80\%). ${ }^{[85]}$ Technical success rate was $89 \%$. In a subset of patients who were followed up, $80 \%, 57 \%$, and $52 \%$ required no further intervention or one additional dilation only at the end of 1,3 , and 5 years, respectively. Cumulative proportions of patients undergoing surgery at 1,3 , and 5 years were $13 \%, 28 \%$, and $36 \%$, respectively. Complication rate per procedure was $5.3 \%$, and included bowel perforation (1.4\%), major bleeding requiring blood transfusion (1\%), minor bleeding $(1.3 \%)$, and abdominal pain or fever $(1.5 \%)$.

\section{Endoscopic Differences between Intestinal Tuberculosis and Crohn's Disease}

Zhou and Luo ${ }^{[86]}$ compared the records of 30 patients of $\mathrm{CD}$ and 30 patients with ITB. The comparison of endoscopic findings among various studies between ITB and CD is presented in Table 4.

Lee et al. ${ }^{[87]}$ evaluated the diagnostic value of colonoscopy in differentiating ITB $(n=44)$ from CD $(n=44)$ and observed that four parameters (anorectal lesions, longitudinal 


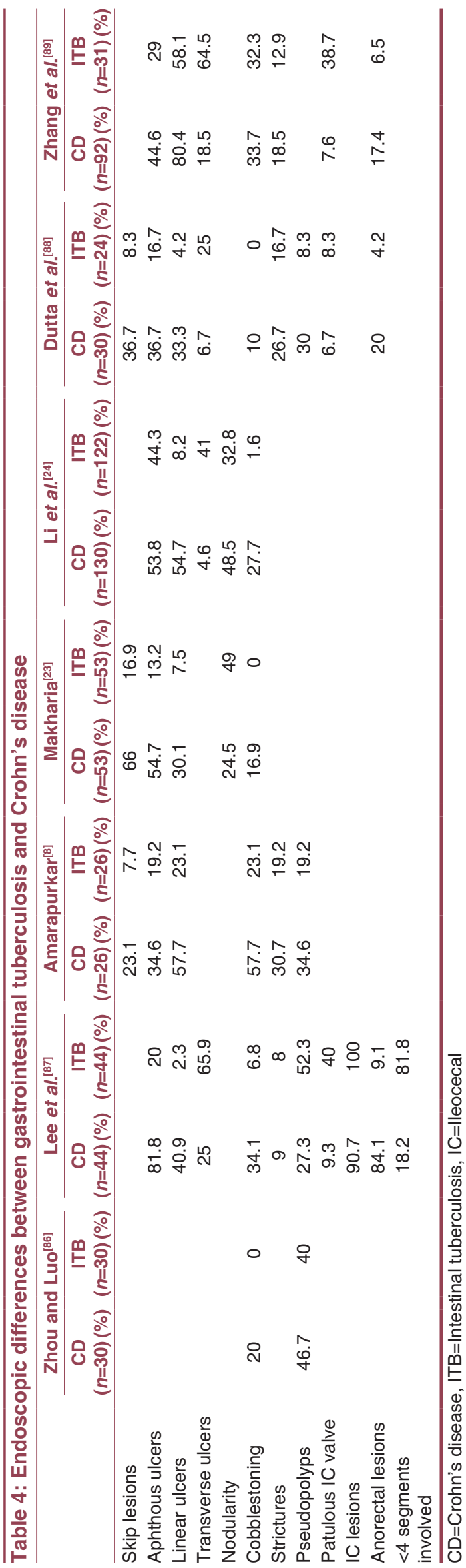

ulcers, aphthous ulcers, and cobblestone appearance) were significantly more common in patients with $C D$ than in patients with ITB. Four other parameters (involvement of fewer than four segments, a patulous IC valve, transverse ulcers, and scars or pseudopolyps) were observed more frequently in patients with ITB than in patients with $C D .{ }^{[87]}$ A patulous valve with surrounding heaped-up folds or a destroyed valve with a fish mouth opening was more likely to be caused by TB than that by $\mathrm{CD}$. In their study, if $\mathrm{CD}$ was diagnosed based on the presence of higher number of parameters characteristic of $\mathrm{CD}$ than those characteristic of ITB, and vice versa, the diagnosis was correct in $87.5 \%$ and incorrect in $8 \% .{ }^{[87]}$

Amarapurkar et al. studied 26 patients with ITB and 26 patients with $\mathrm{CD}$ and found that the accuracy of endoscopic features (deep linear/serpiginous ulcers and cobblestone appearance) was $67.3 \%$ compared to the $84.6 \%$ for clinical score and $82.6 \%$ for positive TB-PCR. ${ }^{[8]}$

We, in a study of 53 patients with intestinal TB and 53 patients with $\mathrm{CD}$, observed that while skip lesions, aphthous ulcers, linear ulcers, and cobblestoning were more common in patients of $\mathrm{CD}$ than that in intestinal TB; nodularity was however more common in those with intestinal TB. ${ }^{[23]}$ We also observed that the involvement of rectum $(62.2 \%$ vs. $18.8 \%, P<0.001)$, sigmoid colon ( $66 \%$ vs. $11.3 \%, P<0.001)$, descending colon (60.3\% vs. $13.2 \%, P<0.001)$, ascending colon $(64.1 \%$ vs. $43.4 \%, P=0.03)$, and jejunum $(16.9 \%$ vs. $0 \%, P<0.001)$ was significantly more common in patients with $\mathrm{CD}$ than in patients with ITB. ${ }^{[23]}$ There was no significant difference in the involvement of the IC region ( $88.6 \%$ vs. $92.4 \%, P=0.5)$, ileum $(24.5 \%$ vs. $15 \%, P=0.2)$, stomach, and duodenum in patients with $\mathrm{CD}$ and intestinal TB. ${ }^{[23]}$

Li et al. ${ }^{[24]}$ in their study including 122 patients with ITB and 130 patients with $\mathrm{CD}$ observed that that rectum and sigmoid colon involved lesions were more common in patients with $\mathrm{CD}$. On the other hand, cecum and IC valve involved lesions and fixed-open IC valve were more often seen in patients with ITB. Ring-like ulcers and rodent-like ulcers were more common in ITB, while longitudinal ulcers, grid-like ulcers, cobblestone appearance, and nodular hyperplasia were more commonly found in CD [Table 4].

Dutta et al. followed up 30 patients of ITB and 30 patients of $\mathrm{CD}$ and reported that patients with $\mathrm{CD}$ had longer duration of symptoms $(P<0.001)$, blood mixed stool $(P=0.006)$, longitudinal ulcers $(P=0.005)$, skip lesions $(P=0.008)$, and involvement of higher number of colonic segments $(P=0.004) \cdot{ }^{[88]} \mathrm{Yu}$ et al ${ }^{[90]}$ studied 43 patients with ITB and 53 patients with $\mathrm{CD}$ and observed that transverse ulcers and patulous IC valve were more common in ITB. Longitudinal ulcer was a significant predictor in differentiating $\mathrm{CD}$ from ITB (odds ratio 35.5, confidence interval 1.8-683.2). 
Zhang et al. ${ }^{[89]}$ also reported that transverse ulcers, rodent-like ulcers, and patulous IC valve were more common in those with ITB and longitudinal ulcers in patients with CD.

The reasons for a greater frequency of involvement of left side of the colon in patients with $\mathrm{CD}$ and occurrence of aphthous ulcers, linear ulcers, cobblestoning of mucosa in higher frequency in $\mathrm{CD}$ and nodularity, patulous IC valve in higher number in those with ITB, are not well known and need more research.

\section{Approach in a Patient Where a Differentiation between Intestinal Tuberculosis and Crohn's disease Cannot Be Made}

The clinical, endoscopic, and histological features that help in differentiation between ITB and CD are summarized in Table 5. From the Table 5, it is obvious that almost all the features are often present in these two conditions and none of the features is pathognomonic of either of the diseases. However, with the use of a combination of these features, one may be able to make a diagnosis of either TB or CD in almost half of the patients.

\begin{tabular}{lcc}
\hline \multicolumn{3}{c}{ Table 5: Clinical, endoscopic and histological differentiation } \\
between intestinal tuberculosis and Crohn's disease \\
\hline Variables & $\begin{array}{c}\text { Intestinal } \\
\text { Tuberculosis (\%) }\end{array}$ & $\begin{array}{c}\text { Crohn's } \\
\text { Disease (\%) }\end{array}$ \\
\hline Chronic diarrhea & $20-40$ & $60-80$ \\
Blood in the stools & $10-20$ & $50-70$ \\
Abdominal pain & 90 & $60-80$ \\
Constipation & 50 & $10-30$ \\
Symptoms & & \\
Partial intestinal obstruction & $50-60$ & $20-30$ \\
Peri-anal disease & 5 & $30-80$ \\
Fever & $40-70$ & 30 \\
Loss of appetite & $40-80$ & $40-60$ \\
Weight loss & $60-90$ & $50-60$ \\
Extra-intestinal manifestations & 10 & $20-50$ \\
Anal canal & $<5$ & $15-50$ \\
Rectum & $10-20$ & $40-60$ \\
Sigmoid colon & $5-10$ & $10-50$ \\
Involvement of Intestine & & \\
Descending colon & $5-10$ & $10-50$ \\
Ascending colon & $40-60$ & $50-70$ \\
Ileocaecal area & $70-90$ & 60 \\
Ileum & $10-20$ & $20-40$ \\
Aphthous ulcers & $5-10$ & $30-50$ \\
Endoscopic features & & $20-30$ \\
Linear ulcers & 5 & $30-40$ \\
Deep ulcers & $50-70$ & 20 \\
Nodularity & 50 & \\
Cobblestoning & None & \\
Histological features & & \\
Granuloma & $10-60$ & \\
Necrosis in the granuloma & & \\
\hline
\end{tabular}

There are situations where differentiation between ITB and $\mathrm{CD}$ is not possible despite extensive investigation. Under these circumstances, both the Asia Pacific Association of Gastroenterology and the Indian Society of Gastroenterology consensus on CD suggest a trial of anti-TB treatment. ${ }^{[20,21]}$ This is based on the rationale that the treatment of TB is finite, whereas treatment for CD continues indefinitely. ${ }^{[20,21]}$ Furthermore, there is a risk in treating patients with corticosteroids if the diagnosis actually is TB. Obviously the decision to treat for one disease or the other would take into account other clinical considerations including the nature of presentation of the patient, whether acutely ill and requiring immediate definitive therapy or not. It would also be accompanied by a complete discussion with the patient of the possibilities and therapeutic alternatives. Compounding the problem of differentiation between intestinal TB and CD and a therapeutic trial of antiTB drugs to resolve the issue, a proportion of patients with $\mathrm{CD}$ also respond to anti-TB therapy at least symptomatically. ${ }^{[91]}$

In patients treated for intestinal $\mathrm{TB}$, it is expected that there will be a complete resolution of the lesions, detectable by endoscopy or by imaging, following therapy. It is, therefore, appropriate to re-endoscope the patients who were treated empirically for ITB and to establish complete mucosal healing at the end of 6 months. ${ }^{[20,21]}$

In summary, while many of endoscopic features overlap in patients with ITB and CD, certain endoscopic features have been identified by most of the investigators as suggestive of $\mathrm{CD}$. These features include involvement of left side of the colon, involvement of multiple segments of the intestine, and presence of longitudinal ulcers and cobblestoning of the mucosa. Healing of the lesions should be demonstrated in patients suspected to have ITB and being treated empirically with anti-TB therapy.

\section{Financial support and sponsorship}

Nil.

Conflicts of interest

There are no conflicts of interest.

\section{References}

1. Sharma SK, Mohan A. Extrapulmonary tuberculosis. Indian J Med Res 2004;120:316-53.

2. Golden MP, Vikram HR. Extrapulmonary tuberculosis: An overview. Am Fam Physician 2005;72:1761-8.

3. Rieder HL, Snider DE Jr., Cauthen GM. Extrapulmonary tuberculosis in the United States. Am Rev Respir Dis 1990;141:347-51.

4. Lazarus AA, Thilagar B. Abdominal tuberculosis. Dis Mon 2007;53:32-8.

5. Kapoor VK, Sharma LK. Abdominal tuberculosis. Br J Surg 1988;75:2-3.

6. Bhansali SK. Abdominal tuberculosis. Experiences with 300 cases. Am J Gastroenterol 1977;67:324-37.

7. Bhansali SK. Gastrointestinal perforations. A clinical study of 96 cases. J Postgrad Med 1967;13:1-12.

8. Amarapurkar DN, Patel ND, Rane PS. Diagnosis of Crohn's disease in 
India where tuberculosis is widely prevalent. World J Gastroenterol 2008;14:741-6.

9. Das K, Ghoshal UC, Dhali GK, Benjamin J, Ahuja V, Makharia GK. Crohn's disease in India: A multicenter study from a country where tuberculosis is endemic. Dig Dis Sci 2009;54:1099-107.

10. Makharia GK, Ramakrishna BS, Abraham P, Choudhuri G, Misra SP, Ahuja V, et al. Survey of inflammatory bowel diseases in India. Indian J Gastroenterol 2012;31:299-306.

11. Epstein D, Watermeyer G, Kirsch R. Review article: The diagnosis and management of Crohn's disease in populations with high-risk rates for tuberculosis. Aliment Pharmacol Ther 2007;25:1373-88.

12. Ouyang Q, Tandon R, Goh KL, Ooi CJ, Ogata H, Fiocchi C. The emergence of inflammatory bowel disease in the Asian Pacific region. Curr Opin Gastroenterol 2005;21:408-13.

13. Jayanthi V, Robinson RJ, Malathi S, Rani B, Balambal R, Chari S, et al. Does Crohn's disease need differentiation from tuberculosis? J Gastroenterol Hepatol 1996;11:183-6.

14. Arnold C, Moradpour D, Blum HE. Tuberculous colitis mimicking Crohn's disease. Am J Gastroenterol 1998;93:2294-6.

15. Kim ES, Song GA, Cho KB, Park KS, Kim KO, Jang BI, et al. Significant risk and associated factors of active tuberculosis infection in Korean patients with inflammatory bowel disease using anti-TNF agents. World J Gastroenterol 2015;21:3308-16.

16. Byun JM, Lee CK, Rhee SY, Kim HJ, Kim JW, Shim JJ, et al. The risk of tuberculosis in Korean patients with inflammatory bowel disease receiving tumor necrosis factor- $\alpha$ blockers. J Korean Med Sci 2015;30:173-9.

17. Andersen NN, Jess T. Risk of infections associated with biological treatment in inflammatory bowel disease. World J Gastroenterol 2014;20:16014-9.

18. Sood A, Midha V. Epidemiology of inflammatory bowel disease in Asia. Indian J Gastroenterol 2007;26:285-9.

19. Pulimood AB, Amarapurkar DN, Ghoshal U, Phillip M, Pai CG, Reddy DN, et al. Differentiation of Crohn's disease from intestinal tuberculosis in India in 2010. World J Gastroenterol 2011;17:433-43.

20. Ramakrishna BS, Makharia GK, Ahuja V, Ghoshal UC, Jayanthi V, Perakath B, et al. Indian Society of Gastroenterology consensus statements on Crohn's disease in India. Indian J Gastroenterol 2015;34:3-22.

21. Ooi CJ, Makharia GK, Hilmi I, Gibson PR, Fock KM, Ahuja V, et al. AsiaPacific consensus statements on Crohn's disease. Part 2: Management. J Gastroenterol Hepatol 2016;31:56-68.

22. Kapoor VK. Abdominal tuberculosis: The Indian contribution. Indian J Gastroenterol 1998;17:141-7.

23. Makharia GK, Srivastava S, Das P, Goswami P, Singh U, Tripathi M, et al. Clinical, endoscopic, and histological differentiations between Crohn's disease and intestinal tuberculosis. Am J Gastroenterol 2010;105:642-51.

24. Li X, Liu X, Zou Y, Ouyang C, Wu X, Zhou M, et al. Predictors of clinical and endoscopic findings in differentiating Crohn's disease from intestinal tuberculosis. Dig Dis Sci 2011;56:188-96.

25. Leder RA, Low VH. Tuberculosis of the abdomen. Radiol Clin North Am 1995;33:691-705.

26. Jarman BT. Small bowel imaging. Surg Clin North Am 2011;91:109-25.

27. Morel P, Alexander-Williams J, Rohner A. Relation between flowpressure-diameter studies in experimental stenosis of rabbit and human small bowel. Gut 1990;31:875-8.

28. Anand BS, Nanda R, Sachdev GK. Response of tuberculous stricture to antituberculous treatment. Gut 1988;29:62-9.

29. Rieder F, Latella G, Magro F, Yuksel ES, Higgins PD, Di Sabatino A, et al. European Crohn's and colitis organisation topical review on prediction, diagnosis and management of fibrostenosing Crohn's disease. J Crohns Colitis 2016;10:873-85

30. Sharma MP, Bhatia V. Abdominal tuberculosis. Indian J Med Res 2004;120:305-15.

31. Haddad FS, Ghossain A, Sawaya E, Nelson AR. Abdominal tuberculosis. Dis Colon Rectum 1987;30:724-35.

32. Chen WS, Su WJ, Wang HS, Jiang JK, Lin JK, Lin TC. Large bowel tuberculosis and possible influencing factors for surgical prognosis: 30 years' experience. World J Surg 1997;21:500-4.

33. Misra SP, Dwivedi M, Misra V, Gupta M, Kunwar BK. Endoscopic biopsies from normal-appearing terminal ileum and cecum in patients with suspected colonic tuberculosis. Endoscopy 2004;36:612-6.

34. Leung VK, Tang WL, Cheung CH, Lai MS. Importance of ileoscopy during colonoscopy for the early diagnosis of ileal tuberculosis: Report of two cases. Gastrointest Endosc 2001;53:813-5.

35. Almadi MA, Ghosh S, Aljebreen AM. Differentiating intestinal tuberculosis from Crohn's disease: A diagnostic challenge. Am J Gastroenterol 2009;104:1003-12.

36. Alvares JF, Devarbhavi H, Makhija P, Rao S, Kottoor R. Clinical, colonoscopic, and histological profile of colonic tuberculosis in a tertiary hospital. Endoscopy 2005;37:351-6.

37. Singh V, Kumar P, Kamal J, Prakash V, Vaiphei K, Singh K. Clinicocolonoscopic profile of colonic tuberculosis. Am J Gastroenterol 1996;91:565-8.

38. Shah S, Thomas V, Mathan M, Chacko A, Chandy G, Ramakrishna BS, et al. Colonoscopic study of 50 patients with colonic tuberculosis. Gut 1992;33:347-51.

39. Marshall JB. Tuberculosis of the gastrointestinal tract and peritoneum. Am J Gastroenterol 1993;88:989-99.

40. Puri AS, Sachdeva S, Mittal VV, Gupta N, Banka A, Sakhuja P, et al. Endoscopic diagnosis, management and outcome of gastroduodenal tuberculosis. Indian J Gastroenterol 2012;31:125-9.

41. Louis E, Collard A, Oger AF, Degroote E, Aboul Nasr El Yafi FA, Belaiche J. Behaviour of Crohn's disease according to the Vienna classification: Changing pattern over the course of the disease. Gut 2001;49:777-82.

42. Farmer RG, Hawk WA, Turnbull RB Jr. Clinical patterns in Crohn's disease: A statistical study of 615 cases. Gastroenterology 1975;68(4 Pt 1):627-35.

43. Wilkins T, Jarvis K, Patel J. Diagnosis and management of Crohn's disease. Am Fam Physician 2011;84:1365-75.

44. Goel A, Dutta AK, Pulimood AB, Eapen A, Chacko A. Clinical profile and predictors of disease behavior and surgery in Indian patients with Crohn's disease. Indian J Gastroenterol 2013;32:184-9.

45. Stange EF, Travis SP, Vermeire S, Beglinger C, Kupcinkas L, Geboes $\mathrm{K}$, et al. European evidence based consensus on the diagnosis and management of Crohn's disease: Definitions and diagnosis. Gut 2006;55 Suppl 1:11-15.

46. Rutgeerts PJ. From aphthous ulcer to full-blown Crohn's disease. Dig Dis 2011;29:211-4.

47. Lorenz-Meyer H, Malchow H, Miller B, Stock H, Brandes JW. European cooperative Crohn's disease study (ECCDS): Colonoscopy. Digestion 1985;31:109-19.

48. Hogan WJ, Hensley GT, Geenen JE. Endoscopic evaluation of inflammatory bowel disease. Med Clin North Am 1980;64:1083-102.

49. Meuwissen SG, Pape KS, Agenant D, Oushoorn HH, Tytgat GN. Crohn's disease of the colon. Analysis of the diagnostic value of radiology, endoscopy, and histology. Am J Dig Dis 1976;21:81-8.

50. Waye JD. Colitis, cancer, and colonoscopy. Med Clin North Am 1978;62:211-24.

51. Oberhuber G, Stangl PC, Vogelsang H, Schober E, Herbst F, Gasche C. Significant association of strictures and internal fistula formation in Crohn's disease. Virchows Arch 2000;437:293-7.

52. Annese V, Daperno M, Rutter MD, Amiot A, Bossuyt P, East J, et al. European evidence based consensus for endoscopy in inflammatory bowel disease. J Crohns Colitis 2013;7:982-1018.

53. Wagtmans MJ, van Hogezand RA, Griffioen G, Verspaget HW, Lamers CB. Crohn's disease of the upper gastrointestinal tract. Neth J Med 1997;50:S2-7.

54. Rutgeerts P, Onette E, Vantrappen G, Geboes K, Broeckaert L, Talloen L. Crohn's disease of the stomach and duodenum: A clinical study with emphasis on the value of endoscopy and endoscopic biopsies. Endoscopy 1980;12:288-94.

55. Diaz L, Hernandez-Oquet RE, Deshpande AR, Moshiree B. Upper 
gastrointestinal involvement in Crohn disease: Histopathologic and endoscopic findings. South Med J 2015;108:695-700.

56. Tony J, Sunilkumar K, Thomas V. Randomized controlled trial of DOTS versus conventional regime for treatment of ileocecal and colonic tuberculosis. Indian J Gastroenterol 2008;27:19-21.

57. Makharia GK, Ghoshal UC, Ramakrishna BS, Agnihotri A, Ahuja V, Chowdhury SD, et al. Intermittent directly observed therapy for abdominal tuberculosis: A multicenter randomized controlled trial comparing 6 months versus 9 months of therapy. Clin Infect Dis 2015;61:750-7.

58. Henriksen M, Jahnsen J, Lygren I, Sauar J, Schulz T, Stray N, et al. Change of diagnosis during the first five years after onset of inflammatory bowel disease: Results of a prospective follow-up study (the IBSEN Study). Scand J Gastroenterol 2006;41:1037-43.

59. Gisbert JP, Bermejo F, Pérez-Calle JL, Taxonera C, Vera I, McNicholl AG, et al. Fecal calprotectin and lactoferrin for the prediction of inflammatory bowel disease relapse. Inflamm Bowel Dis 2009;15:1190-8.

60. Rutgeerts P, Geboes K, Vantrappen G, Kerremans R, Coenegrachts JL, Coremans G. Natural history of recurrent Crohn's disease at the ileocolonic anastomosis after curative surgery. Gut 1984;25:665-72.

61. Rutgeerts P, Geboes K, Vantrappen G, Beyls J, Kerremans R, Hiele M. Predictability of the postoperative course of Crohn's disease. Gastroenterology 1990;99:956-63.

62. Van Assche G, Dignass A, Panes J, Beaugerie L, Karagiannis J, Allez M, et al. The second European evidence-based Consensus on the diagnosis and management of Crohn's disease: Definitions and diagnosis. J Crohns Colitis 2010;4:7-27.

63. Balamurugan R, Venkataraman S, John KR, Ramakrishna BS. PCR amplification of the IS6110 insertion element of Mycobacterium tuberculosis in fecal samples from patients with intestinal tuberculosis. J Clin Microbiol 2006;44:1884-6.

64. Morgan MA, Horstmeier CD, DeYoung DR, Roberts GD. Comparison of a radiometric method (BACTEC) and conventional culture media for recovery of mycobacteria from smear-negative specimens. J Clin Microbiol 1983;18:384-8.

65. Ye BD, Yang SK, Kim D, Shim TS, Kim SH, Kim MN, et al. Diagnostic sensitivity of culture and drug resistance patterns in Korean patients with intestinal tuberculosis. Int J Tuberc Lung Dis 2012;16:799-804.

66. Wilson ML. Rapid diagnosis of Mycobacterium tuberculosis infection and drug susceptibility testing. Arch Pathol Lab Med 2013;137:812-9.

67. Leung VK, Law ST, Lam CW, Luk IS, Chau TN, Loke TK, et al. Intestinal tuberculosis in a regional hospital in Hong Kong: A 10-year experience. Hong Kong Med J 2006;12:264-71.

68. Patel N, Amarapurkar D, Agal S, Baijal R, Kulshrestha P, Pramanik S, et al. Gastrointestinal luminal tuberculosis: Establishing the diagnosis. J Gastroenterol Hepatol 2004;19:1240-6.

69. Anand BS, Schneider FE, El-Zaatari FA, Shawar RM, Clarridge JE, Graham DY. Diagnosis of intestinal tuberculosis by polymerase chain reaction on endoscopic biopsy specimens. Am J Gastroenterol 1994;89:2248-9.

70. Gan HT, Chen YQ, Ouyang Q, Bu H, Yang XY. Differentiation between intestinal tuberculosis and Crohn's disease in endoscopic biopsy specimens by polymerase chain reaction. Am J Gastroenterol 2002;97:1446-51.

71. Bourreille A, Ignjatovic A, Aabakken L, Loftus EV Jr., Eliakim R, Pennazio M, et al. Role of small-bowel endoscopy in the management of patients with inflammatory bowel disease: An international OMEDECCO consensus. Endoscopy 2009;41:618-37.

72. Jensen MD, Nathan T, Rafaelsen SR, Kjeldsen J. Diagnostic accuracy of capsule endoscopy for small bowel Crohn's disease is superior to that of MR enterography or CT enterography. Clin Gastroenterol Hepatol 2011;9:124-9.

73. Reddy DN, Sriram PV, Rao GV, Reddy DB. Capsule endoscopy appearances of small-bowel tuberculosis. Endoscopy 2003;35:99.

74. Cello JP. Capsule endoscopy features of human immunodeficiency virus and geographical diseases. Gastrointest Endosc Clin N Am 2004;14:169-77.

75. Triester SL, Leighton JA, Leontiadis GI, Gurudu SR, Fleischer DE, Hara AK, et al. A meta-analysis of the yield of capsule endoscopy compared to other diagnostic modalities in patients with non-stricturing small bowel Crohn's disease. Am J Gastroenterol 2006;101:954-64.

76. Fidder HH, Nadler M, Lahat A, Lahav M, Bardan E, Avidan B, et al. The utility of capsule endoscopy in the diagnosis of Crohn's disease based on patient's symptoms. J Clin Gastroenterol 2007;41:384-7.

77. Tukey M, Pleskow D, Legnani P, Cheifetz AS, Moss AC. The utility of capsule endoscopy in patients with suspected Crohn's disease. Am J Gastroenterol 2009;104:2734-9.

78. Niv Y, Ilani S, Levi Z, Hershkowitz M, Niv E, Fireman Z, et al. Validation of the Capsule Endoscopy Crohn's Disease Activity Index (CECDAI or Niv score): A multicenter prospective study. Endoscopy 2012;44:21-6.

79. Gal E, Geller A, Fraser G, Levi Z, Niv Y. Assessment and validation of the new capsule endoscopy Crohn's disease activity index (CECDAI). Dig Dis Sci 2008;53:1933-7.

80. Leighton JA, Triester SL, Sharma VK. Capsule endoscopy: A metaanalysis for use with obscure gastrointestinal bleeding and Crohn's disease. Gastrointest Endosc Clin N Am 2006;16:229-50.

81. Levesque BG, Cipriano LE, Chang SL, Lee KK, Owens DK, Garber AM. Cost effectiveness of alternative imaging strategies for the diagnosis of smallbowel Crohn's disease. Clin Gastroenterol Hepatol 2010;8:261-7, 267.e1-4.

82. Mergener K, Ponchon T, Gralnek I, Pennazio M, Gay G, Selby W, et al. Literature review and recommendations for clinical application of smallbowel capsule endoscopy, based on a panel discussion by international experts. Consensus statements for small-bowel capsule endoscopy, 2006/2007. Endoscopy 2007;39:895-909.

83. Erkelens GW, van Deventer SJ. Endoscopic treatment of strictures in Crohn's disease. Best Pract Res Clin Gastroenterol 2004;18:201-7.

84. Hassan C, Zullo A, De Francesco V, Ierardi E, Giustini M, Pitidis A, et al. Systematic review: Endoscopic dilatation in Crohn's disease. Aliment Pharmacol Ther 2007;26:1457-64.

85. Gustavsson A, Magnuson A, Blomberg B, Andersson M, Halfvarson J, Tysk C. Endoscopic dilation is an efficacious and safe treatment of intestinal strictures in Crohn's disease. Aliment Pharmacol Ther 2012;36:151-8.

86. Zhou ZY, Luo HS. Differential diagnosis between Crohn's disease and intestinal tuberculosis in China. Int J Clin Pract 2006;60:212-4.

87. Lee YJ, Yang SK, Byeon JS, Myung SJ, Chang HS, Hong SS, et al. Analysis of colonoscopic findings in the differential diagnosis between intestinal tuberculosis and Crohn's disease. Endoscopy 2006;38:592-7.

88. Dutta AK, Sahu MK, Gangadharan SK, Chacko A. Distinguishing Crohn's disease from intestinal tuberculosis - A prospective study. Trop Gastroenterol 2011;32:204-9.

89. Zhang T, Fan R, Wang Z, Hu S, Zhang M, Lin Y, et al. Differential diagnosis between Crohn's disease and intestinal tuberculosis using integrated parameters including clinical manifestations, T-SPOT, endoscopy and CT enterography. Int J Clin Exp Med 2015;8:17578-89.

90. Yu H, Liu Y, Wang Y, Peng L, Li A, Zhang Y. Clinical, endoscopic and histological differentiations between Crohn's disease and intestinal tuberculosis. Digestion 2012;85:202-9.

91. Munot K, Ananthakrishnan AN, Singla V, Benjamin J, Kedia S, Dhingra $\mathrm{R}$, et al. Response to trial of antitubercular therapy in patients with ulceroconstrictive intestinal disease and an eventual diagnosis of Crohn's disease. Gastroenterology 2011;140:S-159. 